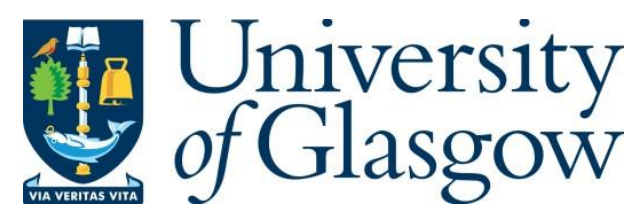

Bensalah, M. et al. (2018) Cortisol evaluation during the acute phase of traumatic brain injury - a prospective study. Clinical Endocrinology, 88(5), pp. 627-636.

There may be differences between this version and the published version. You are advised to consult the publisher's version if you wish to cite from it.

This is the peer reviewed version of the following article: Bensalah, M. et al. (2018) Cortisol evaluation during the acute phase of traumatic brain injury - a prospective study. Clinical Endocrinology, 88(5), pp. 627-636, which has been published in final form at http://dx.doi.org/10.1111/cen.13562. This article may be used for noncommercial purposes in accordance with Wiley Terms and Conditions for SelfArchiving.

http://eprints.gla.ac.uk/157080/

Deposited on: 15 February 2018

Enlighten - Research publications by members of the University of Glasgow http://eprints.gla.ac.uk 
DR MERIEM HAMMOUTENE BENSALAH (Orcid ID : 0000-0002-5787-6076)

Article type $\quad: 3$ Original Article - Australia, Japan, SE Asia

\section{CORTISOL EVALUATION DURING THE ACUTE PHASE OF TRAUMATIC BRAIN INJURY - A PROSPECTIVE STUDY}

Meriem.Bensalah ${ }^{1}$, Malcolm.Donaldson ${ }^{2}$, Yamina.Aribi $^{1}$,Malek.Iabassen ${ }^{1}$,Lyes.Cherfi ${ }^{3}$,Mustap ha.Nebbal ${ }^{4}$, Meriem.Medjaher $^{5}$ ElMehdi.Haffaf $^{5}$, Benaissa.Abdennebi $^{6}$, Mustapha.Guenane $^{7}$, Adel Djermane ${ }^{8}$, Zahra.Kemali ${ }^{1}$,Samia.OuldKablia ${ }^{1}$.

1-Endocrinology unit, Central Hospital of Army Algiers .Algeria.

2-Glasgow University School of Medicine, Glasgow, United Kingdom.

3- Critical care unit, Central Hospital of Army Algiers .Algeria.

4- Neurosurgery unit, Central Hospital of Army Algiers .Algeria.

5- Nuclear medicine unit. Central Hospital of Army Algiers .Algeria.

6- Critical care unit, Salim Zemirli Hospital. Algiers .Algeria.

7- Neurosurgery unit, Salim Zemirli Hospital. Algiers.Algeria.

8-Faculty of medicine of Algiers. Algiers .Algeria.

Corresponding Author: Dr Meriem Bensalah, Endocrinology unit, Central Hospital of Army Algiers .Algeria.

E-mail :meriem_hammoutene@2ic-dz.com

Tel: +213770988788

Fax: +21321830144

This article has been accepted for publication and undergone full peer review but has not been through the copyediting, typesetting, pagination and proofreading process, which may lead to differences between this version and the Version of Record. Please cite this article as doi:

$10.1111 /$ cen. 13562

This article is protected by copyright. All rights reserved. 


\section{Acknowledgments}

The authors thank the doctors and the nurses of neurosurgery and critical care medicine departments of Salim Zemirli hospital and central hospital of army in Algiers. We also thank the patients and their families.

\section{Abstract:}

Background: Biochemical diagnosis of adrenal insufficiency (AI) is difficult in the context of traumatic brain injury (TBI).

Aim: to assess the frequency and predictive factors of AI in victims of TBI from Algiers.

Methods: Between November 2009 and December 2013, TBI victims had a single 8-9 a.m. serum cortisol measurement during the acute post injury period (0-7 days). AI was defined according to basal cortisol levels of 83, 276 and $414 \mathrm{nmol} / \mathrm{L}$. Variables studied were TBI severity according to Glasgow coma scale, duration of intubation and coma, pupillary status, hypotension, anemia, brain imaging findings, diabetes insipidus and medication. Insulin tolerance test was performed during the recovery phase, defining AI as peak cortisol $<500$ $\mathrm{nmol} / \mathrm{L}$.

Results: Cortisol samples were obtained at median 3 (1-7) days from 277 patients (257M: 20F) aged 32 (18-65) years. Acute AI frequency was $8(2.8 \%), 20(21 \%)$ and $35(37 \%)$ respectively using the three cortisol cut-offs. Factors predicting AI were diastolic hypotension, sedative medication, diabetes insipidus, skull base fracture and intraparenchymal haematoma. Mortality was highest in patients with acute cortisol $<276 \mathrm{nmol} / \mathrm{L}$ (44.6\% with OR for death $1.64,95 \%$ CI $0.92-3.0, \mathrm{p}=0.12$ ). During the recovery phase, AI was present in 3/3, 12/24, 4/16 and 20/66 patients with week 1 cortisol <83, 83-276, 277-414 and $>414 \mathrm{nmol} / \mathrm{L}$.

This article is protected by copyright. All rights reserved. 
Conclusion: Hydrocortisone replacement is advised in TBI patients with morning cortisol $<276 \mathrm{nmol} / \mathrm{L}$ or those $<414 \mathrm{nmol} / \mathrm{L}$ with additional risk factors for AI. Since acute and subsequent AI are poorly correlated patients with moderate/severe TBI require adrenal reevaluation during the recovery phase.

\section{Keywords: Traumatic brain injury, adrenal insufficiency, cortisol, skull base fracture, diabetes insipidus, diastolic hypopressure, sedative drugs.}

\section{Introduction}

Traumatic brain injury (TBI) is a major public health problem and the leading cause of disability among young adults [1]. The incidence of TBI in USA is 200 cases /year/100,000 head of population with $10 \%$ requiring hospitalization and 1 in 3 of these patients being admitted to intensive care units [2]. A literature review of 23 reports from Europe showed the overall incidence (range) of hospitalization for TBI to be 235(150-300)/100,000/year [3].

Few data are available for the African continent. In West Africa, road traffic accidents (RTA) are responsible for $80 \%$ of all head traumas in Nigeria alone, while more than half of deaths attributed to head injuries from RTA in Africa occur before patients can be admitted to hospital [1]. In Guinea, a study of 2829 victims of RTA during the year 2009 showed TBI to be present in $82 \%$ of cases with median age 27.1 years [4]. In East Africa, a study from Uganda showed TBI to be the second reason for admission to an intensive care unit, with 1774 patients admitted over 7 years [5].

In the Maghreb countries of North Africa, TBI accounted for $14.4 \%$ of admissions in Tunisia, particularly in young adults, with a mortality rate of $29 \%$ [6].

The hypothalamic-pituitary adrenal axis is activated in response to the critical illness caused by TBI so that initially cortisol levels are increased. However, adrenocorticotrophic hormone 
$(\mathrm{ACTH})$ deficiency can be caused by damage, necrosis and hemorrhage in the hypothalamus and pituitary [7]. Medications used for the management of the victims in the acute phase of brain injury can also induce modifications of cortisol metabolism. Moreover, critical illness may cause a resistance in cortisol action in different tissues caused by cytokine secretion [79].

The biochemical diagnosis of adrenal insufficiency (AI) is difficult in the context of critical illness such as TBI [10]. In particular, the cut-off for basal cortisol values which constitute AI remain controversial. In practice, it is neither feasible nor appropriate to carry out stimulation testing such as insulin tolerance test (ITT) to evaluate the corticotrope axis in critically ill patients with TBI while the corticotropin stimulation test using $250 \mu \mathrm{g}$ may overestimate ACTH function [9]. Moreover, the cut-off for this test is not well established in critical illness [7-8].

It is nevertheless still important to evaluate basal cortisol in TBI despite the lack of consensual cut-offs. There is also a need to determine the predictive factors of AI in TBI since hydrocortisone treatment of truly deficient patients could improve their outcome. The aims of this study, therefore, were to determine the prevalence of AI in the acute phase of TBI according to defined serum cortisol cut-off in an unselected population; to determine what factors predicted low cortisol levels; and hence to develop an algorithm for clinical management. A further aim was to re-evaluate adrenal status during the recovery phase of TBI and hence determine the relationship between acute and subsequent AI.

Methods:

All patients with moderate to severe TBI aged 18-65 years admitted to the Salim Zemirli and Central Army hospitals, two neighboring hospitals in the East of Algiers, between November 2009 and December 2013, were prospectively studied. Exclusion criteria were the presence

This article is protected by copyright. All rights reserved. 
of pre-existing endocrine disease including adrenal or pituitary insufficiency, drug or alcohol abuse, glucocorticoid intake, and chronic illness.

The clinical are of patients enrolled into the study was at the discretion of the attending critical care physicians, and included the prescription of glucocorticoid in selected subjects. Dexamethasone was not given to the patients, in keeping with the evidence to show no benefit and increased mortality in TBI patients in whom steroids were given for intra-cerebral lesions $[10]$.

During the acute post injury period (0-7 days), measurement of serum cortisol was performed in all patients between 8 and 9 a.m. on at least one occasion. Cortisol was assayed using the Cis-bio RIA. Co-efficients of variation $(\mathrm{CVs})$ for intra-assay precision for 20 points were $5.5 \%, 3.6 \%$ and $3.7 \%$ for mean cortisol values of 64,251 and $686 \mathrm{nmol} / \mathrm{l}$. CVs for inter-assay precision of 10 doublets $5.7 \%, 8.1 \%$ and $6.7 \%$ for mean cortisol values of 63,222 and 565 nmol/l.

Adrenal insufficiency was defined using three cortisol cut-offs:

- $83 \mathrm{nmol} / \mathrm{l}$; a value accepted as indicating severe adrenal deficiency [11].

- $276 \mathrm{nmol} / \mathrm{l}$; a value indicating adrenal deficiency in critical illness according to the consensus statements from an international task force by the American College of Critical Care Medicine [12].

- 414nmol/l; a value defined by Cohan et and recommended by Hannon et al as indicating AI in victims of TBI [13,14].

The variables which were studied as potential associations with AI included: age, severity of brain injury; duration of intubation and coma; pupillary status as anisocoria, mydriasis, isocoria; and ischaemic factors in terms of arterial hypotension (systolic and/or diastolic blood pressure $<90$ and $60 \mathrm{mmHg})$ and anemia $(\mathrm{Hb}<9 \mathrm{dg} / \mathrm{ml})$. The severity of TBI was evaluated by GCS [15], graded as severe when GCS was <8, moderate with GCS 8-13. Computerised 
tomography (CT) findings were recorded from the first scan within the first 24 hours; the presence of skull base fracture was noted. Diabetes insipidus was diagnosed in the context of polyuria, hypernatremia $>150 \mathrm{mmol} / \mathrm{l}$ and osmolality $>300 \mathrm{mosmol} / \mathrm{Kg}$ in the absence of osmotic substance administration. The type of medications used for sedation in intubated patients was recorded and comprised: Midazolam (Hypnovel), 2-6-Diisopropilphenol (Propofol), Sodium Thiopental (Penthotal), Fentanyl (Fentanyl) or Sufentanyl (Sufenta) and Phenobarbital (Gardenal).

Outcome of TBI was evaluated by the GOCS (Glasgow Outcome Coma Scale), with a score of 5 for favorable outcome, 4 for moderate disability, 3 for severe disability, 2 for persistent vegetative state, and 1 for death [16].

Adrenal status and wider pituitary function was re-evaluated during the recovery phase, defined as three months after TBI in surviving patients. ITT was performed in the absence of contraindications, e.g. seizures, as recommended by the consensus guidelines on screening for hypopituitarism after brain injury [17]. Insulin was given in the dosage of 0.1 units $/ \mathrm{kg}$ and requiring a glucose nadir of $<2.2 \mathrm{mmol} / \mathrm{L}$ to represent adequate hypoglycaemia.

Sampling was carried out at baseline, 15, 30, 45, 60, 90 and 120 minutes and AI was defined as peak cortisol $<500 \mathrm{nmol} / \mathrm{l}$. Growth hormone deficiency during ITT was defined as a peak value of $<5 \mu \mathrm{g} / \mathrm{L}(15 \mathrm{mIU} / \mathrm{L})$, gonadotrophin deficiency as serum testosterone or estradiol levels below the reference range (testosterone $<8 \mathrm{nmol} / \mathrm{l}$ in males and estradiol $<60 \mathrm{pmol} / \mathrm{l}$ in non-menopausal women with normal/low gonadotrophins, hypoprolactinaemia as prolactin $<73 \mathrm{mIU} / \mathrm{L}$ and hyperprolactinaemia as prolactin $>474 \mathrm{mIU} / \mathrm{L}$ in men and $>502 \mathrm{mIU} / \mathrm{L}$ in women, thyrotropin deficiency as free thyroxine $<6.35 \mathrm{pg} / \mathrm{L}(<8.4 \mathrm{pmol} / \mathrm{L})$ with normal or low TSH.

This article is protected by copyright. All rights reserved. 
Statistical analysis was performed using Student $\mathrm{t}$ test of $\mathrm{CHI}$ tests for between group comparisons. Comparison of means was with ANOVA or Krushall-Wallis test, and Pearson coefficient was used for analyzing quantitative variables. The measure of variance used was the standard deviation. Data analysis was with SPSS version 21. Receiver operator curve (ROC) analysis was carried out to determine the value of acute phase cortisol in predicting cortisol insufficiency (peak stimulated cortisol $<500 \mathrm{nmol} / \mathrm{L}$ ) during the recovery phase.

The Scientific and Ethics Committees of the central hospital of Army and the Medical Faculty of Algiers approved this study. Consent was obtained from the families of patients for cortisol samples to be taken during the acute phase of TBI. Written consent was also obtained from patients (where appropriate) and families for repeat adrenal function testing during the recovery phase.

\section{Results}

Between November 2009 and December a total of 277 Algerian patients with moderate or severe TBI were seen and their details are shown in Table 1.There was a strong male predominance $(93 \%)$ in the study population, age ranging from 18 to 65 years. RTA was the most frequent cause of brain injury, occurring in $48 \%$ of patients (M: 128, F: 4). Ninety-eight patients $(35.5 \%)$ died (GOCS $=1$ ) after a median hospital admission of $10.4 \pm 11.6$ days including 45 (45.9\%) deaths during the first week. However, half of the patients $(n=140)$ had a good outcome with GOCS 5.

\section{Data relating to neurological status during acute phase of TBI:}

Of the 277 patients, 144 (48\%) had moderate and 133(52\%) severe TBI according to GCS, and $177(63.8 \%)$ were intubated for a mean period of $7.2 \pm 11$ days. Mean duration of coma was $9.54 \pm 16.5$ days. 95 (34. $3 \%)$ of the patients had multiple injuries while $116(42 \%)$ had intracranial surgery. During the first week 85 (30.7\%) of the patients had anemia with $\mathrm{Hb}<$ 
9g/dl and $64(29.1 \%)$ were hypotensive with systolic or diastolic blood pressure $<90 / 60$ mmg $\mathrm{Hg}$ on admission to the intensive care unit. Concerning pupillary status, 169 patients (61\%) had isocoric pupils with anisocoria in $61(22 \%)$ and mydriasis in $47(17 \%)$. CT imaging showed complex lesions in 224 patients associated with fractures, arachnoid hemorrhage and hematoma while 58 patients had isolated intra-parenchymal hematoma and $53(19.1 \%)$ had skull base fracture.

Eight patients developed diabetes insipidus during the first week, all of whom died. During the post-traumatic acute phase $168(60.6 \%)$ patients were sedated with Midazolam $(n=155)$, Propofol $(n=5)$, Penthotal ( $n=25)$, Fentanyl or Sufentanyl $(n=162)$ and Phenobarbital $(n=7)$.

\section{Cortisol data during the acute phase of TBI (See Figure 1):}

A single cortisol sample was taken during the acute phase of TBI from all 277 patients with a median (range) time at sampling of 3 (1-7) Analysis using one-way ANOVA showed no significant differences in the cortisol levels according to the day of sampling $(p=0.32)$. Mean morning cortisol was $573.1 \pm 376 \mathrm{nmol} / \mathrm{l}$ and there was no difference between patients with severe and moderate TBI: $541.9 \pm 308.1$ versus $606.9 \pm 436.8 \mathrm{nmol} / \mathrm{l}(\mathrm{p}=0.15)$. Serum cortisol was $\leq 83 \mathrm{nmol} / 1$ in $8(2.9 \%)$ patients, $\leq 276 \mathrm{nmol} / 1$ in $56(20.2 \%)$ and $\leq 414 \mathrm{nmol} / 1$ in 98 $(35.4 \%)$

Seven patients were given hydrocortisone replacement at the discretion of their attending physicians ; four with cortisol levels $<83 \mathrm{nmol} / \mathrm{l}$ and three with cortisol $<276 \mathrm{nmol} / \mathrm{l}$ in whom hemodynamic instability was present. No patient with cortisol $>414 \mathrm{nmol} / \mathrm{l}$ received glucocorticoids.

This article is protected by copyright. All rights reserved. 


\section{Factors associated with low cortisol cut-offs during acute phase of TBI (see table 2)}

Table 2 shows the bivariate analysis comparing the patients with and without post traumatic AI according to the three chosen cut-off levels of cortisol. No association could be found between the three cortisol cut-offs and severity of TBI according to GCS or pupillary status. However, the presence of intra-parenchymal haematoma was predictive of AI for all three cortisol cut-offs. Diastolic blood pressure $<60 \mathrm{mmHg}$ was associated with AI for the 83 and 276 but not the $414 \mathrm{nmol} / \mathrm{l}$ cut-offs There was no significant association between anemia and AI but acute insipidus diabetes was associated with AI at the $414 \mathrm{nmol} / \mathrm{l}$ cut-off level.

The prescription of Pentothal and Propofol in sedated patients was associated with cortisol level $<83 \mathrm{nmol} / \mathrm{l}$, indicating a strong correlation (p: 0. 00004-p: 0.022). These findings were not found for the other agents.

Multiple extracranial injuries and cranial surgery were not associated with posttraumatic AI. Mortality was not significantly associated with AI for the three cortisol cut-offs. However, the highest mortality was seen in patients with acute cortisol <276nmol/1 (44.6\% with OR for death of $1.64,95 \%$ CI $0.92-3.0, p=0.12$ )

\section{Adrenal axis function during the recovery phase of TBI (see Figure2):}

Figure 2 shows the outcome of adrenal testing during the recovery phase, grouped according to cortisol cut-off values during the acute phase of TBI. Of 179 patients who survived TBI repeat testing was successfully carried out three months later in 133 (74\%). AI was found in all 3 surviving patients with initial cortisol $<83 \mathrm{nmol} / \mathrm{l}$ and in 12/24 and 4/16 patients with acute phase cortisols of $84-276$ and $277-414 \mathrm{nmol} / \mathrm{l}$. AI was also found in 20/66 (30\%) patients with initial cortisol $>414 \mathrm{nmol} / \mathrm{l}$.

ROC curve analysis showed no meaningful correlation between acute cortisol and the response to ITT three months later indicating that no acute cortisol cut-off was of predictive value.

This article is protected by copyright. All rights reserved. 


\section{Pituitary function during recovery phase}

The overall prevalence of post traumatic hypopituitarism three months after injury was $44 \%$ with corticotrophin deficiency in $39(29,3 \%)$ patients; growth hormone deficiency in 24 (18\%); gonadotrophin deficiency in 9 (6.8\%); hypoprolactinemia in 9 (6.8\%); hyperprolactinaemia in $5(3.8 \%)$ and thyrotropin deficiency in $2(1.5 \%)$.

\section{Discussion}

TBI is an important public health problem and remains the leading cause of handicap and disability in young adults [2]. Victims are usually young adult males with RTA and falls being the most frequent causes [1,2]. The prevalence of TBI in Algeria is unknown, but the frequency of RTA is ranked among the top five countries in the world, with 3000 deaths and 25,700 injured during 2016 [18] .

The outcome in severe TBI is generally poor, and the presence of neuroendocrine complications may further worsen the prognosis $[12,13]$. Early diagnosis of AI in TBI is therefore important since timely recognition and treatment may improve the prognosis. While AI in the setting of TBI is well-recognized [14], the cut-off values for cortisol defining its presence remains problematic.

Serum cortisol is typically increased during the acute phase of TBI. Levels of $>550 \mathrm{nmol} / \mathrm{l}$ $(20 \mu \mathrm{g} / \mathrm{dl})$ are usual and have been linked to increased mortality [19]. Increased secretion due to activation of the corticotrophin axis, mediated by hypothalamic CRF secretion in response to stress $[8,9]$, is one explanation for this finding. Another proposed mechanism is cortisol resistance in target tissues, caused by the increased cytokine secretion which occurs in response to brain injury $[8,9]$. The use of medication in the acute phase of TBI may also modify cortisol metabolism both by inhibiting steroidogenesis and by acting as enzymatic inducers $[8,13]$.

This article is protected by copyright. All rights reserved. 
Cortisol levels of $<83-138 \mathrm{nmol} / \mathrm{l}$ during the acute phase of TBI clearly demonstrate an impaired response of the adrenal axis to stress and indicate AI. However, values $>138 \mathrm{nmol} / \mathrm{l}$ cannot exclude the possibility of AI especially in critical illness; indeed the appropriate cutoff level defining AI is still not established [8, 13, 14].

Table 3 shows data from fifteen studies of cortisol levels in acute TBI. The American College of Critical Care Medicine, after a literature review, proposed a cortisol cut-off $276 \mathrm{nmol} / \mathrm{l}$ as level defining adrenal deficiency in critical illness [11]. Cohan et al advised using a 414 nmol/l $(15 \mu \mathrm{d} / \mathrm{dl})$ cut-off to confirm AI in acute TBI after a study in which 80 victims were compared with a control group [13]. Hannon et al recommended the same cut-off level for defining post traumatic AI [14].

Mean cortisol in our sample of patients was $573.1 \pm 376.2 \mathrm{nmol} / \mathrm{l}$ and is in keeping with other studies $[13,20,21]$. Lower values were reported by authors who evaluated cortisol levels in TBI victims without prior exclusion of patients receiving glucocorticoids [22, 23].

In the present study, the prevalence for the lowest cortisol cut-off level of $83 \mathrm{nmol} / \mathrm{l}$ was $2.9 \%$, almost identical with the prevalence reported in other studies [19, 24, 25].

For the middle cortisol cut-off of $276 \mathrm{nmol} / \mathrm{l}$, the prevalence of AI was $20.2 \%$ in our study, contrasting with the higher figures of $54 \%$ and $70 \%$ prevalence values reported by Olivecrona et al on the first and fourth post TBI days [26] and the lower prevalence of $9.8 \%$ reported by Tanriverdi et al [21]. These discrepancies are at least partly explained by variation in the severity of TBI in the different studies. Thus, Olivecrona et al described 48 patients with severe TBI - GCS $<8$ and intracranial pressure $>10 \mathrm{mmHg}$ [26]; while Tanriverdi et al, using a $200 \mathrm{nmol} / \mathrm{l}$ cortisol cut-off, studied 52 patients with minimal, moderate and severe TBI during the first 24 hours [21].

This article is protected by copyright. All rights reserved. 
For the top cut-off level of $414 \mathrm{nmol} / \mathrm{l}$, the prevalence frequency of AI in our study was 35.4 $\%$, compared with $53 \%$ in the study of Cohan et al who measured cortisol twice daily for the first nine days in 80 victims of moderate to severe TBI [13].

Hannon et al studied 100 TBI victims aged 18-75 years with GCS $<14$ and compared them with 50 controls, measuring cortisol at admission and during the ten consecutive days. Cortisol levels in controls was $>500 \mathrm{nmol} / 1$ whereas $78 \%$ of injured patients had values $<300$ $\mathrm{nmol} / \mathrm{l}$ on the first day which was still low in $63 \%$ patients on the $3^{\text {rd }}$ day. Cortisol levels increased thereafter at the 10 day after injury in 41 of patients (61. 5\%) [27].

As shown in table 3, some authors have evaluated the corticotrophin axis using dynamic tests and shown a degree of $\mathrm{AI}$ in 4 to $24 \%$ of cases, depending on the time of testing, the populations studied and the severity of TBI.

In our study, re-evaluation of adrenal status was carried out in nearly three quarters of surviving patients. AI was found in all three survivors with the lowest cortisol cut-off of $<83$ $\mathrm{nmol} / \mathrm{l}$, half of the 24 survivors with acute phase cortisol values of $84-276 \mathrm{nmol} / \mathrm{l}$ and in only 4 of the 16 patients with initial cortisol $277-414 \mathrm{nmol} / 1$. However, $30 \%$ of the patients with initial cortisol $>414 \mathrm{nmol} / \mathrm{l}$ fulfilled the criteria for AI on retesting showing the poor predictive value of acute phase cortisol in response to ITT three months later.

These data are consistent with acute AI being transient in some cases due to factors such as medication and hemodynamic disability while true corticotrophin deficiency from pituitary damage may have resolved three months later with resolution of contusion to pituitary tissue. By contrast, corticotrophin deficiency may develop in some patients during the recovery phase of TBI. This pattern of evolving AI has been reported by Tanriverdi et al who reported that pituitary hormone deficiencies recovered in 30 (57.7\%) patients after one year, while new pituitary hormone deficiencies were present in 27 (51.9\%) patients after one year [21]. 
Schneider et al studied 1242 victims of TBI and showed that acute adrenal deficiency could resolve but could also develop five months after the event [33].

The factors linked with AI in the context of brain injury include GCS, anemia, hypotension, pupillary status, cranial lesion, skull base fracture, cranial surgery and intra-cerebral pressure. Cohan et al have reported a correlation between AI and GCS $<13$ [13], a finding supported by the present study and three other studies $[18,22,26]$. Ischaemic factors such as anemia, hypoxia and hypotension are known to cause pituitary damage in Sheehan's syndrome [7, 8]. In this study, we found that diastolic hypotension but not anemia was predictive of acute posttraumatic AI. Similarly, Cohan et al found a positive correlation between AI and mean blood pressure of $<60 \mathrm{mmHg}$ but not for hypoxia and anemia [13].

We found a relationship between the presence of intra-parenchymal hematoma and posttraumatic acute AI but this was not found by Agha or Olivecrona [24,26]. We also found a relationship between skull base fracture and AI for cortisol cut-offs of 276 and $83 \mathrm{nmol} / \mathrm{l}$. This finding is consistent with fractures through the skull base and the sella turcica directly injuring the pituitary gland and inducing corticotrophin deficiency.

Finally, we found that among the medications used in sedation during the acute phase of TBI, Pentothal and Propofol were strong predictors of acute post-traumatic AI. This is consistent with data from Cohan et al who found an association with

Pentobarbital and Propofol and posttraumatic AI [13]. High dose use of Propofol and Pentobarbital induce an inhibition of steroid genesis while Phenobarbital is an enzymatic inducer. In situations where these agents interfere with the corticotrophin axis, the challenge is to distinguish between medication-induced or organic posttraumatic AI since this will affect the need and the duration for steroid treatment. For this reason, Cohan et al. recommend monitoring cortisol levels in intubated patients with traumatic head injury, particularly those receiving high dose of Pentobarbital or Propofol [13].

This article is protected by copyright. All rights reserved. 
Polytrauma was studied as a risk factor for AI in our series given its potential effect on haemodynamic status which could in turn result in pituitary necrosis. However, neither this factor nor cranial surgery could not be shown to affect the prevalence of posttraumatic AI The frequency of posttraumatic diabetes insipidus was $2.8 \%$ in our study, consistent with the $2.9 \%$ prevalence reported by Boughey et al [344]. This contrasts markedly to the very high figure of $26 \%$ in 50 TBI victims described by Agha et al and may be explained by the high proportion of patients with severe injury (64\%) in that study [24]. Diabetes insipidus in TBI is usually transient, lasting between hours and several days although some studies have shown permanent deficiency. In fact. Agha reported the persistence of diabetes insipidus in 8 of 23 victims of TBI 6 to 36 months after injury with an incidence of $6.9 \%$ while Aimaretti showed a similar incidence three months after TBI $[24,35]$.

In the present study, the presence of DI was correlated with acute AI for cortisol levels less than of $414 \mathrm{nmol} / \mathrm{l}$, the putative mechanism being ischaemic or haemorrhagic insult to the posterior and anterior pituitary causing both DI and corticotrophin deficiency. All the patients with DI in our study had severe brain injury with GCS $<8$ and all died.

An association between acute posttraumatic AI and mortality could not be shown in our study, in keeping with the work of Della Corte et al and Olivecrona et al. [26, 28] and in contrast to Hannon et al [14]. Nor could we confirm the work of Kakatti et al who showed a correlation between elevated cortisol levels of $>23 \mu \mathrm{g} / \mathrm{dl}(634 \mathrm{nmol} / \mathrm{l})$ and increased mortality [19]. Nevertheless, the higher mortality seen in those of our patients with acute cortisol <276 nmol/L has influenced our recommendations for clinical care as shown below.

Figure 3 shows a proposed algorithm for the acute and subsequent adrenal evaluation of patients with moderate and severe TBI, and which takes account of the findings of this and other studies.

This article is protected by copyright. All rights reserved. 
In patients with AI risk factors such as diastolic hypotension, intra-parenchymal hematoma, diabetes insipidus, skull base fracture, and the prescription of sedatives such as Penthotal and Propofol we recommend immediate cortisol sampling. This should be followed by hydrocortisone cover in those patients with cortisol $<276 \mathrm{nmol} / \mathrm{L}$ given that mortality was higher in such patients. We also advise cortisol cover in patients with cortisol $<414 \mathrm{nmol} / \mathrm{L}$ in whom AI risk factors persist given the Cohan recommendations [13-14] and recognizing that cortisol values of $<500 \mathrm{nmol} / \mathrm{L}$ in stressed patients with TBI are relatively low [19]. The rationale for choosing the $<414 \mathrm{nmol} / \mathrm{l}$ in patients with no AI risk factors, a serum cortisol should be taken during the first week. Given the poor correlation between acute and subsequent AI, and the significant incidence of hypopituitarism shown in this study 3 months after TBI we recommend pituitary re-evaluation in all patients with moderate and severe TBI during the recovery period, irrespective of adrenal status during the acute phase.

\section{Acknowledgments}

The authors thank the doctors and the nurses of neurosurgery and critical care medicine departments of Salim Zemirli hospital and central hospital of army in Algiers. We also thank the patients and their families'. We thank Professor A.M Aouni and Doctor I. Ararem for their statistical help. We thank Professor Tim Cole for statistical guidance.

\section{References :}

1. León-Carrión. J, Domínguez-Morales M, del R. Barroso y Martín. J. M, Murillo-Cabezas F. Epidemiology of traumatic brain injury and subarachnoid hemorrhage. Pituitary 8.2005; 8: 197-202.

This article is protected by copyright. All rights reserved. 
2. Delemer B, Touraine P. Traumatic brain injury and pituitary insufficiency. Ann. Endocrinol. (Paris).2006; 67: 310-315.

3. Tagliaferri F, Compagnone C, Korsic M., Servadei F, Kraus J. A systematic review of brain injury epidemiology in Europe. Acta Neurochir. (Wien).2006; 148: 255-267.

4. Beavogui K, Koïvogui A, Souare I. S, Camara D, Cherif M, Dramou B, Toure A.A, Diallo R, Guilavogui V, Metellus P. Profile of cranio-cerebral trauma and spinal cord trauma related road accidents in Guinea. Neurochirurgie. 2012; 58: 287-292.

5. Mujuni E, Wangoda R, Ongom P, Galukande M. Acute traumatic coagulopathy among major trauma patients in an urban tertiary hospital in sub Saharan Africa. BMC Emerg. Med. 2012; 14:12. 16.

6. Bahloul M, Chelly H, Ben Hmida M, Ben Hamida C, Ksibi H, Kallel. H, Chaari A. Kassis. M, Rekik N, Bouaziz M. Prognosis of traumatic head injury in South Tunisia: a multivariate analysis of 437 cases. J Trauma .2004; 57:255-261.

7. Dusick J. R, Wang C, Cohan P, Swerdloff. R, Kelly D. F. Pathophysiology of hypopituitarism in the setting of brain injury. Pituitary. 2012; 15: 2-9.

8. Cooper M. S, Stewart P. M. Corticosteroid Insufficiency in Acutely Ill Patients. N. Engl. J. Med.2003; 20: 727-734.

9. Abdu T. a, Elhadd T. a, Neary R, Clayton R. N. Comparison of the low dose short synacthen test ( 1 microg). The conventional dose short synacthen test (250 microg) and the insulin tolerance test for assessment of the hypothalamo-pituitary-adrenal axis in patients with pituitary disease. J. Clin. Endocrinol. Metab.1999; 84: 838-843.

10. Edwards P, Arango M, Balica L, Cottingham R, El-Sayed H, Farrell B, Fernandes J, Gogichaisvili T, Golden N, Hartzenberg B, Husain M, Ulloa MI, Jerbi Z, Khamis H, Komolafe E, Laloë V, Lomas G, Ludwig S, Mazairac G, Muñoz Sanchéz Mde L, Nasi L, Olldashi F, Plunkett P, Roberts I, Sandercock P, Shakur H, Soler C, Stocker R, Svoboda P, 
Trenkler S, Venkataramana NK, Wasserberg J, Yates D, Yutthakasemsunt S; CRASH trial collaborators. Final results of MRC CRASH, a randomised placebo-controlled trial of intravenous corticosteroid in adults with head injury-outcomes at 6 months. Lancet. 2005; $365: 1957-9$

11. Carmichael D J. in the Pituitary (ed. Melmed. S.) 343-373 (Masson Elsevier. 2011).

12. Marik P. E, Pastores S M, Annane D Meduri GU, Sprung CL, Arlt W, Keh D, Briegel J, Beishuizen A, Dimopoulou I, Tsagarakis S, Singer M, Chrousos GP, Zaloga G, Bokhari F, Vogeser M. Recommendations for the diagnosis and management of corticosteroid insufficiency in critically ill adult patients: consensus statements from an international task force by the American College of Critical Care Medicine. Crit. Care Med. 2008; 36: 19371949.

13. Cohan P, Wang. Christina McArthur, David L. Acute secondary adrenal insufficiency after traumatic brain injury: a prospective study. Crit. Care Med. 2005; 33: 2358-2366.

14-Hannon M. J, Sherlock M \& Thompson C. J. Cook SW, Dusick JR, Armin B, Swerdloff R, Vespa P, Muizelaar JP, Cryer HG, Christenson PD, Kelly DF. Pituitary dysfunction following traumatic brain injury or subarachnoid haemorrhage - In 'Endocrine Management in the Intensive Care Unit'. Best Pract. Res. Clin. Endocrinol. Metab.2011; 25, 783-798.

15. Teasdale G. the Glasgow Coma Scale at 40 years: standing the test of time. Lancet. Neurol. 2014; 13. 844-54.

16. Jennett B, Bond M. Assessment of outcome after severe brain damage. Lancet .1975; 1: 480-4.

17. Ghigo,E. MasselB, Aimaretti G, Léon-Carrión J, Casanueva FF, Dominguez-Morales MR, Elovic E, Perrone K, Stalla G, Thompson C, Urban R. Consensus guidelines on screening for hypopituitarism following traumatic brain injury. Brain Inj.2005; 19, 711-724.

18. http://www.dgsn.dz/ -Statistiques (in French).

This article is protected by copyright. All rights reserved. 
19. Arindom Kakati, Bhagavatula Indira Devi. V. B, Pramila Kalra. D. S. Endocrine dysfunction following traumatic brain injury in acute stage. Indian J. neurotrauma .2013; 10: 92-96.

20. Klose M, Juult A, Struck J, Morgenthaler NG, Kosteljanetz M, Feldt-Rasmussen U. Acute and long-term pituitary insufficiency in traumatic brain injury: A prospective single-centre study. Clin. Endocrinol. (Oxf). 2007; 67: 598-606.

21. Tanriverdi F, Hakan S, Kursad U Casanueva FF, Kelestimur F. High risk of hypopituitarism after traumatic brain injury: a prospective investigation of anterior pituitary function in the acute phase and 12 months after trauma. J. Clin. Endocrinol. Metab. 2006; 91: $2105-2111$.

22. Hackl J. M, Gottardis M Wieser. C, Rumpl E, Stadler C, Schwarz S, Monkayo R. Endocrine abnormalities in severe traumatic brain injury--a cue to prognosis in severe craniocerebral trauma? Intensive Care Med.1991; 17: 25-9.

23. Krahulik D, Zapletalova J, Frysak Z, Vaverka. M.Dysfunction of hypothalamichypophysial axis after traumatic brain injury in adults. J. Neurosurg. 2010. 113: 581-584.

24. Agha A,Rogers B, Mylotte D, Taleb F,Tormey W,Phillips J,Thompson CJ. Neuroendocrine dysfunction in the acute phase of traumatic brain injury. Clin. Endocrinol. (Oxf). 2004; 60: 584-591.

25. Prasanna. K. L, Mittal. R. S, Gandhi. A. Neuroendocrine dysfunction in acute phase of moderate-to-severe traumatic brain injury: A prospective study. Brain Inj.2015; 29: 336-342. 26. Olivecrona Z, Dahlqvist P, Koskinen L.-O. D. Acute neuro-endocrine profile and prediction of outcome after severe brain injury. Scand. J. Trauma. Resusc. Emerg. Med.2013; 21: 33 .

27. Hannon M. J, Crowley R. K.Behan L A, O'Sullivan EP, O'Brien MM, Sherlock M, Rawluk D, O'Dwyer R, Tormey W, Thompson CJ. Acute glucocorticoid deficiency and 
diabetes insipidus are common after acute traumatic brain injury and predict mortality. J. Clin. Endocrinol. Metab. 2013; 98: 3229-3237.

28.Della Corte F, Mancini A,Valle D Gallizzi F, Carducci P, Mignani V, De Marinis L. Provocative hypothalamopituitary axis tests in severe head injury: correlations with severity and prognosis. Crit. Care Med.1998; 26: 1419-26.

29. Cernak I, Savic V. J, Lazarov A, Joksimovic M , Markovic S. Neuroendocrine responses following graded traumatic brain injury in male adults. Brain Inj.1999; 13: 1005-1015.

30. Dalwadi PP, Bhagwat NM, Tayde PS, Joshi AS, Varthakavi PK. Pituitary dysfunction in traumatic brain injury: Is evaluation in the acute phase worthwhile? Indian J Endocr Metab $2017 ; 21: 80-4$.

31. Dimopoulou I, Alevizopoulou P, Dafni U, Orfanos S, Livaditi O, Tzanela M, Kotanidou A, Souvatzoglou E, Kopterides P, Mavrou I, Thalassinos N, Roussos C, Armaganidis A, Tsagarakis S . Pituitary-adrenal responses to human corticotropin-releasing hormone in critically ill patients. Intensive Care Med. 2007; 33: 454-459.

32. Dimopoulou I, Tsagarakis S, Douka, Zervou M, Kouyialis AT, Dafni U, Thalassinos N, Roussos C. E. The low-dose corticotropin stimulation test in acute traumatic and nontraumatic brain injury: Incidence of hypo-responsiveness and relationship to outcome. Intensive Care Med. 2004; 30: 1216-1219.

33. Schneider H. J, Schneider M, Kreintschmann I, Tuschy U, Wallaschofski H, Fleck S, Faust M, Renner CI, Kopczak A, Saller B, Buchfelder M, Jordan M, Stalla GK. Structured assessment of hypopituitarism after traumatic brain injury and aneurysmal subarachnoid hemorrhage in 1242 patients: the German interdisciplinary database. J. Neurotrauma .2011; 28. 1693-1698.

34. Boughey J. C, Yost M. J. \& Bynoe R. P. Diabetes insipidus in the head-injured patient. Am. Surg. 2004; 70:500-3.

This article is protected by copyright. All rights reserved. 
35. Aimaretti G, .Abrosio MR, Di Somma C, Gasperi M, Cannavò S, Scaroni C, Fusco A, Del Monte P, De Menis E, Faustini-Fustini M, Grimaldi F, Logoluso F, Razzore P, Rovere S, Benvenga S, Degli Uberti EC, De Marinis L, Lombardi G, Mantero F, Martino E, Giordano G, Ghigo E.Residual pituitary function after brain injury-induced hypopituitarism: A prospective 12-month study. J. Clin. Endocrinol. Metab. 2005;90: 6085-6092 .

This article is protected by copyright. All rights reserved. 
Table 1. Characteristics of 277 patients during the acute phase of traumatic brain injury seen in two Algerian hospitals between November 2009 and December 2013. Data are shown as mean \pm standard deviation. ${ }^{1}$ Abbreviations: $\mathrm{M}=$ male, $\mathrm{F}=$ female, GCS = Glasgow coma scale, GOCS = Glasgow outcome coma scale, TBI = Traumatic brain injury, RTA =road traffic accident, $\mathrm{Hy}=$ Hypnovel, $\mathrm{Pt}=$ Pentothal, Ft=Fentanyl/Sufentanyl, $\mathrm{Pr}=$ Propofol, $\mathrm{Gr}=$ Gardenal.

\begin{tabular}{|c|c|c|c|}
\hline Studied Parameters & \multicolumn{3}{|c|}{ Results } \\
\hline Sex & \multicolumn{3}{|c|}{$\mathrm{M}: 257 \quad \mathrm{~F}: 20$} \\
\hline Age (years) & \multicolumn{3}{|c|}{$31.85 \pm 11.1$} \\
\hline $\begin{array}{l}\text { Severity of TBI }(\mathrm{GCS})^{1} \\
<8 \\
8-13\end{array}$ & \multicolumn{3}{|l|}{$\begin{array}{l}144(52 \%) \\
133(48 \%)\end{array}$} \\
\hline $\begin{array}{l}\text { Causes of TBI } \\
\text { RTA } \\
\text { Fall } \\
\text { Explosion } \\
\text { Other } \\
\end{array}$ & \multicolumn{3}{|l|}{$\begin{array}{l}48 \% \\
23.8 \% \\
6.5 \% \\
21.5 \%\end{array}$} \\
\hline Anemia & \multicolumn{3}{|l|}{$85 \quad(30.7 \%)$} \\
\hline Sedation & \multicolumn{3}{|l|}{$168(60.64 \%)$} \\
\hline Drugs used for sedation & $\begin{array}{ll}\mathrm{Hy}^{1} & \mathrm{Pt}^{1} \\
\mathrm{Gr}^{1} & \\
155 & 25 \\
\end{array}$ & $\begin{array}{r}\mathrm{Ft}^{1} \\
162 \quad 5\end{array}$ & $\begin{array}{l}\operatorname{Pr}^{1} \\
7\end{array}$ \\
\hline Diastolic hypotension & \multicolumn{3}{|l|}{$46(16.6 \%)$} \\
\hline Systolic hypotension & \multicolumn{3}{|l|}{$18(12.5 \%)$} \\
\hline $\begin{array}{l}\text { Pupillary status } \\
\text { Isocoria-Anisocoria-Mydriasis }\end{array}$ & $169-61$ & 47 & \\
\hline Mean intubation duration & \multicolumn{3}{|c|}{$7.2 \pm 11$ days } \\
\hline Mean coma duration & \multicolumn{3}{|c|}{$9.54 \pm 16.52$ days } \\
\hline Diabetes insipidus & \multicolumn{3}{|c|}{$8(2.8 \%)$} \\
\hline Intraparenchymal hematoma & \multicolumn{3}{|l|}{$58(20.93 \%)$} \\
\hline Skull base fracture & \multicolumn{3}{|l|}{$53(19.13 \%)$} \\
\hline $\begin{array}{l}\text { Glasgow outcome coma scale } \\
\text { (GOCS) }{ }^{1}\end{array}$ & \multicolumn{3}{|l|}{$\begin{array}{l}1: 98 \\
2-3-4: 39 \\
5: 140 \\
\end{array}$} \\
\hline
\end{tabular}

This article is protected by copyright. All rights reserved. 
Table 2: Bivariate analysis of factors predicting Adrenal insufficiency (AI) using three chosen cortisol cut-offs: 83 , 276 and 414 nmol/L. Significance for differences was set at $p$ values $<0.05$. Glasgow outcome coma score (GOCS) of 1 equates to mortality, and GOCS2-3-4-5 refers to surviving patients

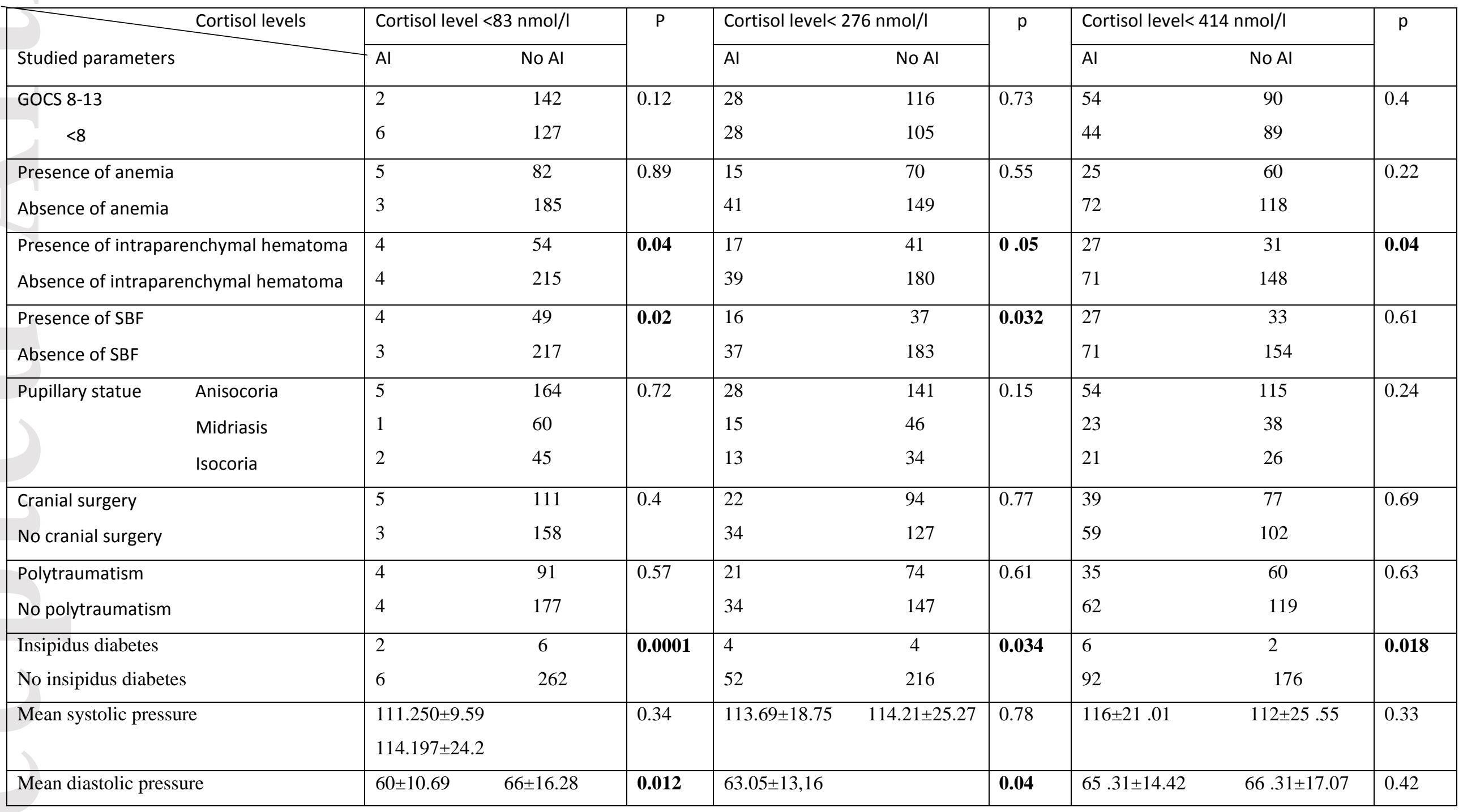

This article is protected by copyright. All rights reserved. 


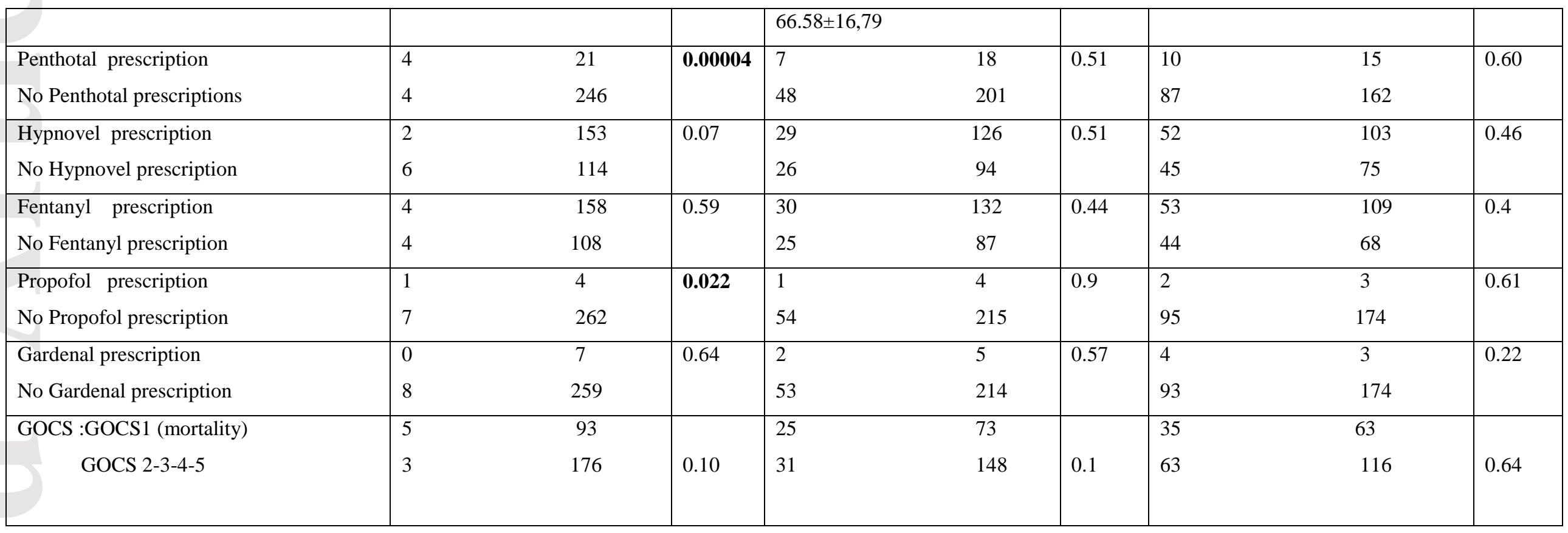

This article is protected by copyright. All rights reserved. 
Table 3. Frequencies of acute AI in the setting of TBI reported in the literature. Mean cortisol values are expressed in nmol/l \pm SDS. The method of evaluation of corticotrophin function, cut offs used in every study and time of testing are given.

\begin{tabular}{|c|c|c|c|c|c|}
\hline $\begin{array}{c}\text { Author \& Year } \\
\text { [reference] }\end{array}$ & $\begin{array}{l}\text { Number of patients } \\
\text { Mean age }\end{array}$ & Day of sampling & $\begin{array}{l}\text { Parameter measured } \\
\text { Cortisol cut-off used (nmol/l) }\end{array}$ & Mean cortisol (nmol/l) & $\% \mathrm{AI}$ according to cut-off \\
\hline Hackl 1991 [24] & $\begin{array}{l}21 \\
30.5 \text { years }\end{array}$ & Acute phase & Cortisol & 126.5 & $\mathrm{NA}^{3}$ \\
\hline Della Corte 1998 [28] & 22 & D1- D7-D15 ${ }^{2}$ & Cortisol & 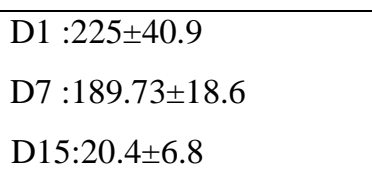 & NA \\
\hline Cernak 1999 [29] & 31 & D7 & Cortisol <200nmol/1 & $318.60 \pm 10.056$ & $100 \%$ if $\mathrm{GCS}<7$ \\
\hline Agha 2004 [24] & $\begin{array}{l}50 \\
37 \pm 14 \text { years }\end{array}$ & D7-D20 & Cortisol + Glucagon test Cortisol $<450 \mathrm{nmol} / 1$ & $496 \pm 218$ & $16 \%$ \\
\hline Cohan 2005 [13] & $\begin{array}{l}80 \\
29 \text { years }\end{array}$ & D1-D9 & Cortisol <414nmol/1 & $588.6-553.5$ & $53 \%$ \\
\hline Tanriverdi 2006 [21] & $\begin{array}{l}52 \\
40.7-34.7-36.6 \text { years }\end{array}$ & $24 \mathrm{~h}$ & Cortisol <200nmol/l & $580.5 \pm 496.8$ & $9.8 \%$ \\
\hline Dimopoulou 2004 [32] & $\begin{array}{l}37 \\
45 \text { years }\end{array}$ & Mean of 16 days & Synacthen $1 \mu \mathrm{g}<500 \mathrm{nmol} / 1$ & 419 & $13 \%$ \\
\hline Klose 2007[20] & $\begin{array}{l}46 \\
38 \text { years }\end{array}$ & D1-D12 & Synacthen $250 \mu \mathrm{g}$ Cortisol<500nmol $/ 1$ & $491(98-1275)$ & $4 \%$ \\
\hline Krahulik 2010 [23] & $\begin{array}{l}186 \\
16-65 \text { years }\end{array}$ & Acute phase & Cortisol- ACTH & NA & $10 \%$ \\
\hline
\end{tabular}

${ }^{2}$ Abbreviations: $\mathrm{D}=$ day, $\mathrm{NA}=$ not available

This article is protected by copyright. All rights reserved. 


\begin{tabular}{|c|c|c|c|c|c|}
\hline Schneider $2011[34]$ & $\begin{array}{l}1242 \\
45.1 \text { years }\end{array}$ & $\begin{array}{l}<5 \text { months post } \\
\text { TC }\end{array}$ & Cortisol + Synathen $250 \mu \mathrm{g}$ & NA & $\begin{array}{l}3 \% \text { (cortisol) } \\
15 \% \text { (synacthen } 250 \mu \mathrm{g} \text { ) }\end{array}$ \\
\hline Olivecrona 2013[26] & $\begin{array}{l}48 \\
35.7 \pm 2.2 \text { years }\end{array}$ & D1-D4 & Cortisol <276nmol/l & 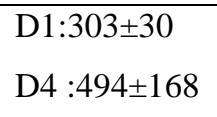 & $\begin{array}{l}54 \% \\
70 \%\end{array}$ \\
\hline Hannon 2013[14] & $\begin{array}{l}100 \\
33 \text { years }\end{array}$ & D1-D10 & Cortisol <300nmol/l & $300-550$ & $78 \%$ \\
\hline Kakati 2013[19] & $\begin{array}{l}30 \\
38 \pm 19.1 \text { years }\end{array}$ & D1 & Cortisol <138nmol/l & NA & $3.3 \%$ \\
\hline Prasanna 2015[25] & 100 & D1 & Cortisol<138nmol/1 & NA & $2 \%$ \\
\hline Dalwadi 2017[30] & 49 & D1 & Cortisol <200nmol/1 & NA & $12.24 \%$ \\
\hline $\begin{array}{l}\text { Present study } \\
2015\end{array}$ & $\begin{array}{l}277 \\
32 \text { years }\end{array}$ & D1-D7 & Cortisol $<83 \mathrm{nmol} / \mathrm{l}-276 \mathrm{nmol} / \mathrm{l}-414 \mathrm{nmol} / \mathbf{l}$ & $573.07 \pm 376$ & $2.8 \% .20 .2 \% .35 .3 \%$ \\
\hline
\end{tabular}

This article is protected by copyright. All rights reserved. 


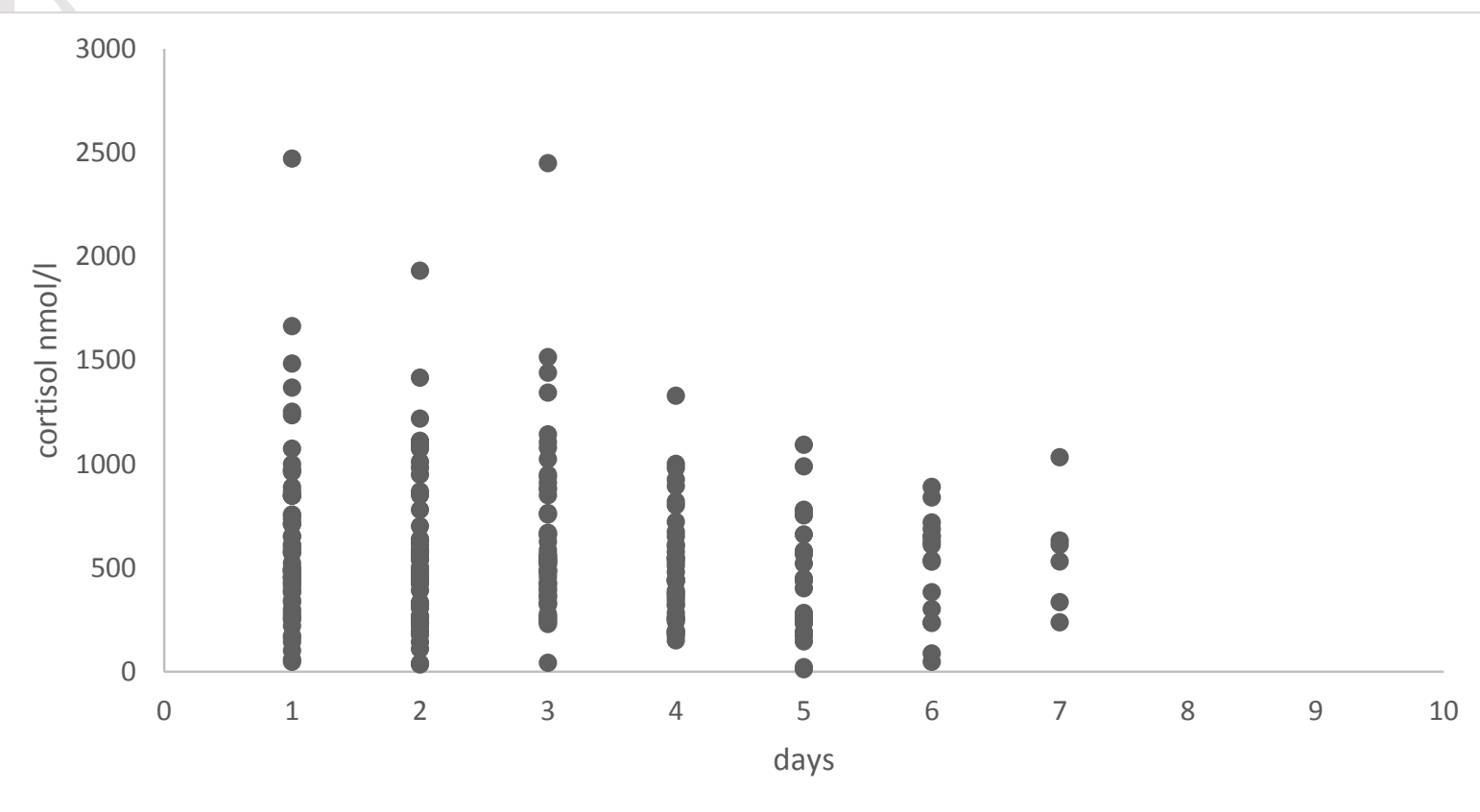

Figure 1: distribution of 277 samples of cortisol during the acute phase of TBI.

Each point corresponds to a single cortisol sample from each patient between days 1 and 7 .

This article is protected by copyright. All rights reserved. 
Total patients with TBI $n=277$

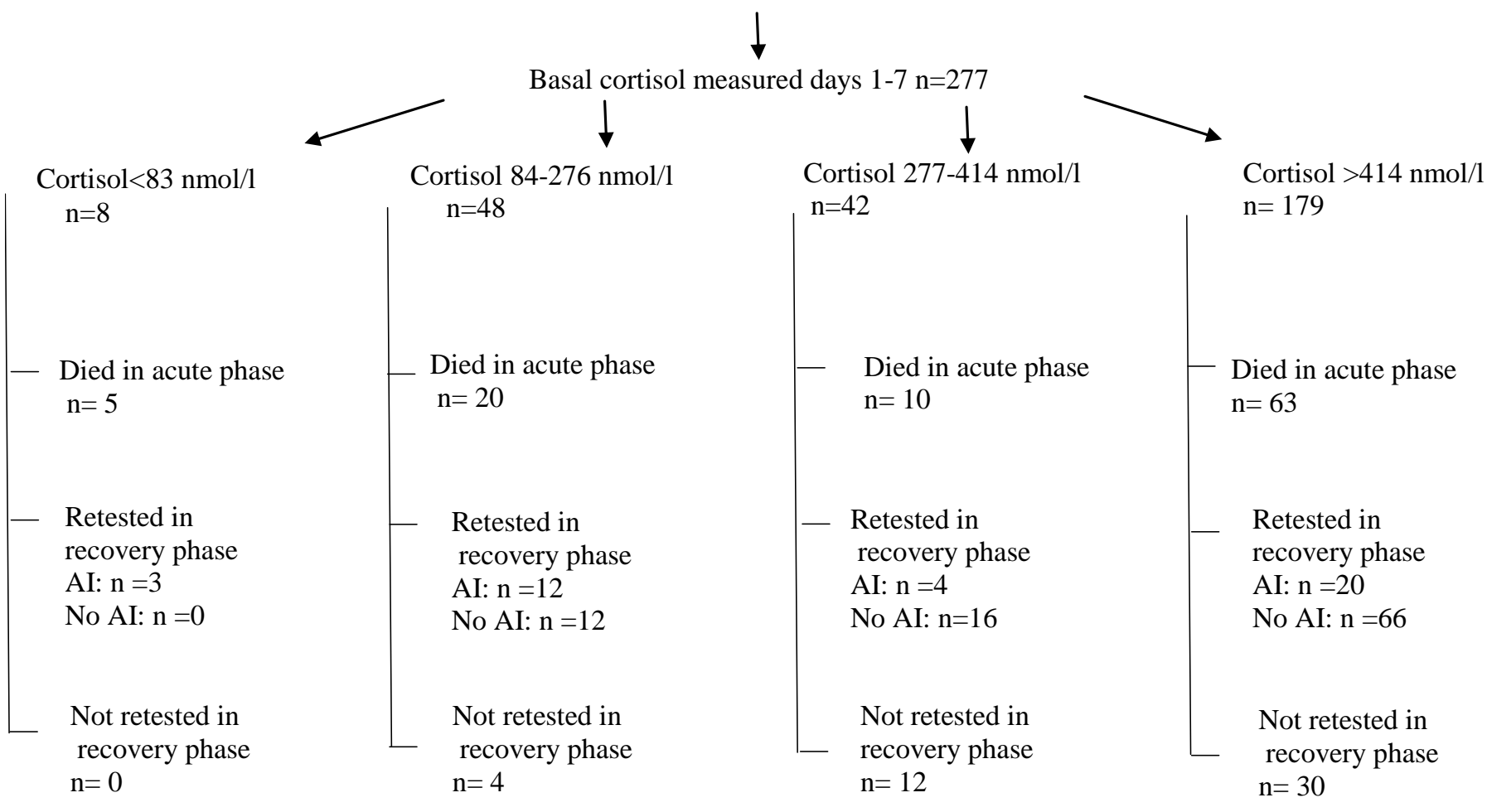

Figure 2: Corticotropin evaluation in the recovery phase of traumatic brain injury group using the insulin tolerance test. Patients are grouped according to serum cortisol level during the acute phase of brain injury. Adrenal insufficiency (AI) during the recovery phase was defined as peak cortisol $<500$ $\mathrm{nmol} / \mathrm{L}$.

This article is protected by copyright. All rights reserved. 


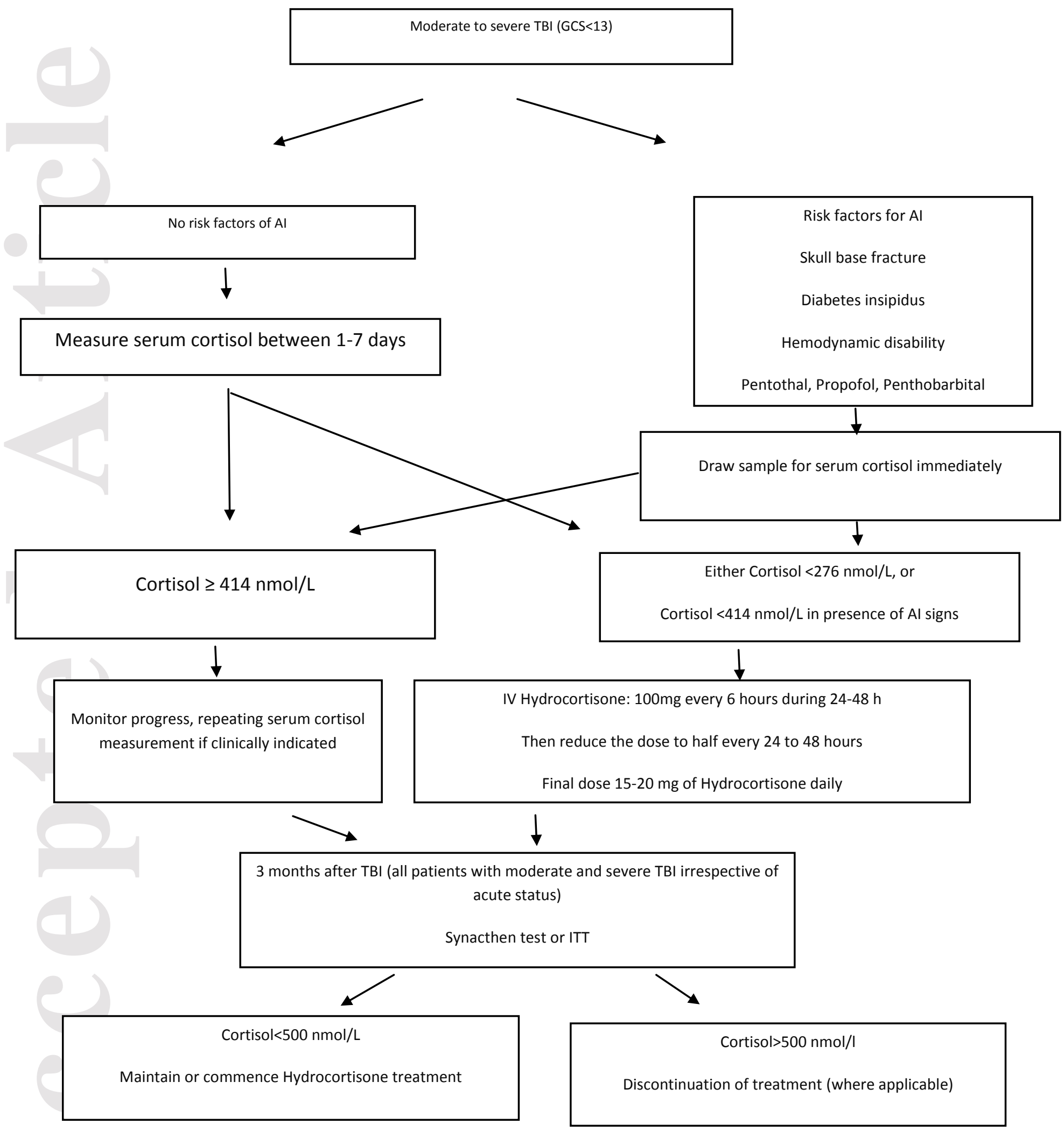

Figure 3: Proposed algorithm for the management of acute adrenal insufficiency (AI) following traumatic brain injury (TBI).

This article is protected by copyright. All rights reserved. 